\title{
Crystallization kinetics of mullite formation in diphasic gels containing different alumina components
}

\author{
Emilija Tkalcec ${ }^{\mathrm{a}, *}$, Hrvoje Ivankovic ${ }^{\mathrm{a}}$, Ruediger Nass ${ }^{\mathrm{b}}$, Helmut Schmidt $^{\mathrm{b}}$ \\ ${ }^{a}$ Faculty of Chemical Engineering and Technology, University of Zagreb, 19 Marulicev trg, HR 10000 Zagreb, Croatia \\ ${ }^{\mathrm{b}}$ Institut fuer Neue Materialien, Im Stadtwald, Gebäude 43, Saarbruecken, D 66123, Germany
}

\begin{abstract}
The crystallization kinetics of mullite formation in diphasic gels containing TEOS derived amorphous silica and alumina com ponent in different crystalline form and particle size has been studied using quantitative X ray diffraction (QXRD) with 3:2 mullite as a standard and transmission electron microscopy (TEM). As the source of alumina component, aluminum nitrate nonahydrate, commercial $\gamma \mathrm{Al}_{2} \mathrm{O}_{3}$ and boehmite $(\gamma \mathrm{AlOOH})$ were used. The results were consistent with previous studies which indicated that mullite forms initially by nucleation and growth. During the second slow stage of transformation, mullite with approximate $2: 1$ composition subsequently converts further into 3:2. This process is the fastest in the precursor with the smallest particle size of alumina, and the slowest in the sample with boehmite derived alumina. In very fine scale of morphology the conversion of $2: 1$ mullite started even in the first stage of transformation.
\end{abstract}

Keywords: Grain size; Kinetics; Mullite; Phase development; Sol gel processes

\section{Introduction}

Mullite has recently become a candidate as a hightemperature structural ceramic, because of its good mechanical strength and creep resistance at high temperature. ${ }^{1}$ A variety of crystallization reactions have been reported for the preparation of mullite. There are three sequences for mullite crystallization by sol-gel processes; (i) direct crystallization from an amorphous phase, which occurs when the precursor is homogeneous at the atomic level (single-phase gels), (ii) crystallization via spinel phase, or (iii) reaction of discrete crystalline or semicrystalline alumina and amorphous silica when the precursors are homogeneous on nanometer levels (diphasic gels). Diphasic gels designated by Schneider ${ }^{2}$ as type II precursors consist of pseudo-boehmite and amorphous silica at room temperature. It is generally accepted that the transformation of pseudo-boehmite follows the same phase transformation sequence as that in boehmite forming $\delta-\mathrm{Al}_{2} \mathrm{O}_{3}$ which then reacts with amorphous silica to form mullite above $1250{ }^{\circ} \mathrm{C}$. Diphasic gels designated as type III precursors are non-

\footnotetext{
* Corresponding author. Fax: + 38514597250.

E mail address: etkalcec@pierre.fkit.hr (E. Tkalcec).
}

crystalline up to $980{ }^{\circ} \mathrm{C}$ and mullite formation is preceded by the formation of a weak crystalline transient alumina such as cubic $\mathrm{Al}-\mathrm{Si}$ spinel or $\gamma-\mathrm{Al}_{2} \mathrm{O}_{3}$ at $980{ }^{\circ} \mathrm{C}$ which later reacts with amorphous silica forming mullite at $<1250{ }^{\circ} \mathrm{C}$.

Crystallization kinetics of mullite from diphasic gels in the system $\mathrm{Al}_{2} \mathrm{O}_{3}-\mathrm{SiO}_{2}$ have been investigated by several groups. ${ }^{3-10}$ Wei and Halloran ${ }^{3}$ studied reaction kinetics and phase transformation mechanism of a diphasic gel type II by quantitative X-ray diffraction of annealed samples and described kinetics by an Avrami equation with an average time exponent $n=1.3$ and a temperature-dependent growth rate of spherical mullite grains. Li and Thomson ${ }^{4,5}$ analyzed kinetic mechanisms from different sol-gel precursors using dynamic X-ray diffraction and differential thermal analysis (DTA) and found a significant change in the activation energy with the $\mathrm{Al} / \mathrm{Si}$ ratio. Huling and Messing ${ }^{6}$ investigated "hybrid" (diphasic + single-phase) gels, and analyzed the influence of various seedings on the crystallization of aluminosilicate phases. Transformation kinetics in technical Nextel 440 fibres containing some $\mathrm{B}_{2} \mathrm{O}_{3}$ have been investigated by Hildmann et al. ${ }^{7}$ According to the authors, the presence of $\mathrm{B}_{2} \mathrm{O}_{3}$ may be responsible for the decrease of viscosity of the coexisting non-crystalline 
$\mathrm{SiO}_{2}$-rich phase, by which diffusion, and nucleation and growth of mullite are accelerated. Hong and Messing ${ }^{8}$ have studied mullite transformation kinetics in $\mathrm{P}_{2} \mathrm{O}_{5^{-}}$, $\mathrm{TiO}_{2}$ - and $\mathrm{B}_{2} \mathrm{O}_{3}$-doped aluminosilicate gels and they observed that $\mathrm{TiO}_{2}$ and $\mathrm{B}_{2} \mathrm{O}_{3}$ reduces the activation energies for both nucleation and growth, and boria specially affected the mullite nucleation process by a much smaller grain size. According to these authors, enhanced transformation kinetics in boria-doped samples may be due to the increase of alumina dissolution into amorphous silica.

The difference in the activation energy found by various authors could be partially due to different crystallization processes and partially to differences in the experimental conditions used in the determination of activation energy. There is an agreement that the formation and growth of mullite from diphasic aluminosilicate gels occurs via a nucleation and growth mechanism, however, the controlling step of this process is the subject of controversy. Wei and Halloran ${ }^{3}$ reported that the mullite transformation in diphasic gels is either interface controlled or short-range diffusion controlled. $\mathrm{Li}$ and Thomson ${ }^{4}$ also agree with the diffusion limited rate model. However, Huling and Messing ${ }^{6}$ suggest that the presence of $\mathrm{Al}-\mathrm{Si}$ spinel in the matrix controls the mullite formation. Sundarasen and Aksay ${ }^{9}$ re-analyzed the data in literature and provided several arguments that support alumina dissolution as the ratelimiting step of mullite growth in diphasic gels. Sacks et al. ${ }^{11}$ discussed all mentioned mechanisms, and also concluded that the dissolution of alumina is apparently the rate controlling step of mullitization.

The theories that are the basis for the analysis of isothermal transformation kinetics are the work of Johnson and Mehl $^{12}$ and Avrami ${ }^{13-15}$ which together comprise the JMA theory. ${ }^{16}$

The aim of this work is to report the effect of type and particle size of alumina component on transformation kinetics and microstructure evolution of sol-gel derived diphasic mullite gels containing alkoxy-derived silica. The crystallization kinetics of mullite has been studied by quantitative X-ray diffraction analysis (QXRD). The microstructure and morphology of the prepared gels and isothermally treated samples has been investigated by transmission electron microscopy (TEM) and energy dispersive X-ray spectrometry (EDXS).

\section{Experimental procedure}

\subsection{Sample preparation}

Three precursors with stoichiometric 3:2 mullite composition $\left(3 \mathrm{Al}_{2} \mathrm{O}_{3} \times 2 \mathrm{SiO}_{2}\right)$ but with different level of mixing were prepared as follows: the gel $\mathrm{M} 1$ was prepared by dissolving $\mathrm{Al}\left(\mathrm{NO}_{3}\right)_{3} \times 9 \mathrm{H}_{2} \mathrm{O}$ in water (nitrate/water molar ratio equals 1:24). The solution was stirred and refluxed at $60{ }^{\circ} \mathrm{C}$ overnight. Tetraethoxysilane (TEOS, Fluka >98 wt.\%) previously mixed with ethanol $($ TEOS/ethanol molar ratio $=1 / 4)$ was added dropwise to the nitrate solution and the stirring was continued for the next $12 \mathrm{~h}$ whereupon the mixture was brought to $\mathrm{pH} 6$ by adding $2 \mathrm{M}$ aqueous ammonia.

Gels M2 and M3 were synthesized from $\gamma-\mathrm{Al}_{2} \mathrm{O}_{3}$ ("Aluminium oxide C" Degusa, mean primary particle size $13 \mathrm{~nm}$, BET $100 \mathrm{~m}^{2} / \mathrm{g}$ ) and $\gamma-\mathrm{AlOOH}$, boehmite, ("Disperal" Condea Chemie, BET $188 \mathrm{~m}^{2} / \mathrm{g}$ ), respectively. Both powders were peptized by adding of $0.1 \mathrm{M}$ aqueous $\mathrm{HNO}_{3}$ solution in a concentration of $10 \mathrm{wt} . \%$. The suspensions were then stirred and refluxed for $24 \mathrm{~h}$ at $60{ }^{\circ} \mathrm{C}$. Stoichiometric amount of $1 \mathrm{M}$ tetraethoxysilane (TEOS, Fluka >98 wt.\%) in ethanol was dropwise added and gelation was carried out by refluxion at $60{ }^{\circ} \mathrm{C}$ for 8 days.

All prepared gels were further dried at $110^{\circ} \mathrm{C}$ for $72 \mathrm{~h}$ and stored in a vacuum dessicator.

\subsection{Sample characterization}

The mullite transformation temperature was evaluated by heating dried gels in platinum cups in a differential thermal system Netzsch Model 409 under the constant synthetic air flow of $75 \mathrm{~cm}^{3} \mathrm{~min}^{-1}$, at the heating rate of $5^{\circ} \mathrm{C} \mathrm{min}^{-1}$.

XRD analysis was performed on a computer controlled diffractometer (Siemens D500/PSD) using $\mathrm{Cu} K_{\alpha}$ radiation with a quartz single-crystal monochromator, and a curved position sensitive detector. Data were collected between 5 and $70^{\circ} 2 \theta$ in step scan mode with step of $0.02^{\circ}$ and counting time of $10 \mathrm{~s} / \mathrm{step}$. The extent of mullite transformation was measured by quantitative XRD of the isothermally treated powders containing 10 wt. $\% \mathrm{CaF}_{2}$ as an internal standard. The integrated intensities of (120) and (210) doublet reflection of mullite and (111) reflection of $\mathrm{CaF}_{2}$ were measured and the ratio compared with the standard $3: 2$ mullite $/ \mathrm{CaF}_{2}$ calibration curve. To establish the calibration curve, mullite was prepared by heat treatment of stoichiometric (3:2) single-phase gel at $1600{ }^{\circ} \mathrm{C}$ for $5 \mathrm{~h}$. The EDX analysis showed that it amounts to $60.2 \mathrm{~mol} \%$ $\mathrm{Al}_{2} \mathrm{O}_{3}$ and $39.8 \mathrm{SiO}_{2}$. This is very near to the theoretical value for $3: 2$ mullite $\left(60.0 \mathrm{~mol}^{\%} \mathrm{Al}_{2} \mathrm{O}_{3}\right.$ and $40.0 \mathrm{~mol} \%$ $\mathrm{SiO}_{2}$ ). Errors in the percent transformation was estimated as 2 wt. $\%$ based on repeated measurements under the same conditions. For the determination of activation energy, the samples were calcined at $700{ }^{\circ} \mathrm{C}$ for $9 \mathrm{~h}$ placed in a $\mathrm{Pt}$ crucible and inserted in a preheated tube furnace and subsequently isothermally heat treated at various temperatures between 1200 and $1300{ }^{\circ} \mathrm{C}$. XRD broadening measurements were performed to determine mullite crystallite size. The mean crystallite 
size of mullite was determined by Scherrer formula ${ }^{17}$ measuring the full with at the half-maximum for (120), (210) and (111) mullite reflections. The morphology of calcined gels and isothermally treated samples were examined using transmission electron microscope (TEM) and energy dispersive X-ray analyzer (EDX) (Jeol 6400 F.)

\section{Results}

Designation of the gels, the source of alumina and silica, and EDX analysis of dried gels are given in Table 1.

In gel M1 pseudoboehmite needles about $10 \mathrm{~nm}$ long were observed at room temperature. Between 10 and 20 $\mathrm{nm}$ long thin plates of $\mathrm{g}-\mathrm{Al}_{2} \mathrm{O}_{3}$ were found in commercial "Aluminium oxide C", whereas boehmite needles in the sample M3 are about $30-40 \mathrm{~nm}$ long. (TEM micrographs are given elsewhere). ${ }^{18}$ DTA analysis of the studied precursors is shown in Fig. 1. The temperature interval at which the isothermal experiments has been performed for gels M2 and M3 is stretched between 1260 and $1320{ }^{\circ} \mathrm{C}$, while it is positioned between 1190 and $1250{ }^{\circ} \mathrm{C}$ for the gel $\mathrm{M} 1$. The maximum isothermal temperature for the gel M1 was limited by the value of incubation time (it was only $10 \mathrm{~s}$ at $1250^{\circ} \mathrm{C}$ ). The activation energy for mullite crystallization was determined using conventional isothermal method in which values for nucleation and growth were deduced from the temperature dependence of the incubation time $(t)$, and the rate constant $(k)$, respectively.

The activation energy for nucleation $E_{a}^{N}$ was calculated from Eq. (1).

$\tau=\tau_{0} \exp \left(\frac{E_{a}^{N}}{R T}\right)$

where $\tau_{0}$ is a constant, $R$ the gas constant, and $T$ absolute temperature. The incubation time, $\tau$, is difficult to determine precisely because of the high uncertainty in determination of the initial state of the transformation process. In this study, the incubation time was obtained by extrapolating the transformation curve of the measured data to the $0 \%$ transformation level.

The activation energy for nucleation and growth $\left(E_{a}^{N G}\right)$ was calculated using Eqs. (2) and (3):

$1=\alpha=\exp \left[-(k(t-\tau))^{n}\right]$

$k=k_{0} \exp \left(-\frac{E_{a}^{N G}}{R T}\right)$

where $\alpha$ is the volume fraction of crystallized mullite, $t$ the firing time (in seconds) $n$ an Avrami exponent and $k_{0}$ a constant. The results of the isothermal heat treatments are shown in Figs. 2, 3 and 4. As shown in the figures the samples exhibit two step behavior; a steep increase of mullite at the beginning of crystallization, and apparently smaller slope at prolonged firing times.

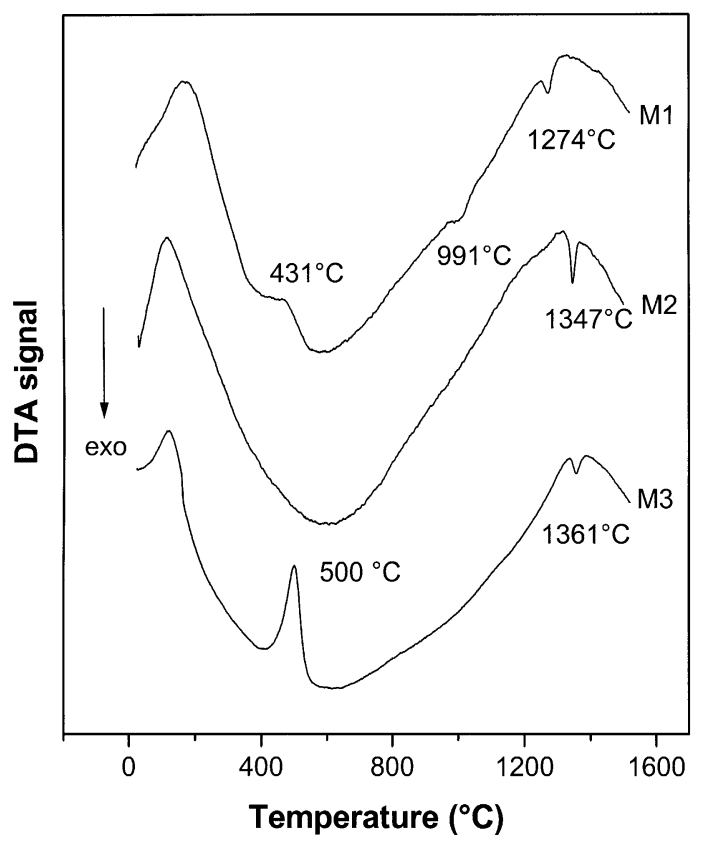

Fig. 1. DTA scans of dried mullite gels recorded at a heating rate of $5 \mathrm{~K} \min { }^{1}$.

Table 1

Designation of dried gels, alumina and silica sources and EDX analysis

\begin{tabular}{|c|c|c|c|c|}
\hline Gel & Type of gels & Al precursor/solvent & Si precursor/solvent & $\begin{array}{l}\text { EDX analysis } \\
\mathrm{Al}_{2} \mathrm{O}_{3} / \mathrm{SiO}_{2} \text { wt. } \%\end{array}$ \\
\hline M1 & $\begin{array}{l}\text { Diphasic coprecipated gel } \\
\text { (combination of type II and } \\
\text { type III gel) })^{\mathrm{a}}\end{array}$ & $\begin{array}{l}\left(\mathrm{Al}\left(\mathrm{NO}_{3}\right)_{3} \cdot 9 \mathrm{H}_{2} \mathrm{O} / \text { water }\right. \\
\text { (pseudoboehmite) }\end{array}$ & TEOS/EtOH & $72.1 / 27.9$ \\
\hline $\mathrm{M} 2$ & Diphasic, type $\mathrm{II}^{\mathrm{a}}$ & $\gamma \mathrm{Al}_{2} \mathrm{O}_{3} /$ water & TEOS/EtOH & $71.7 / 28.3$ \\
\hline M3 & Diphasic, type II $^{\mathrm{a}}$ & Boehmite/water & TEOS/EtOH & $72.1 / 27.9$ \\
\hline
\end{tabular}

a Classifications according to Schneider. ${ }^{2}$ 


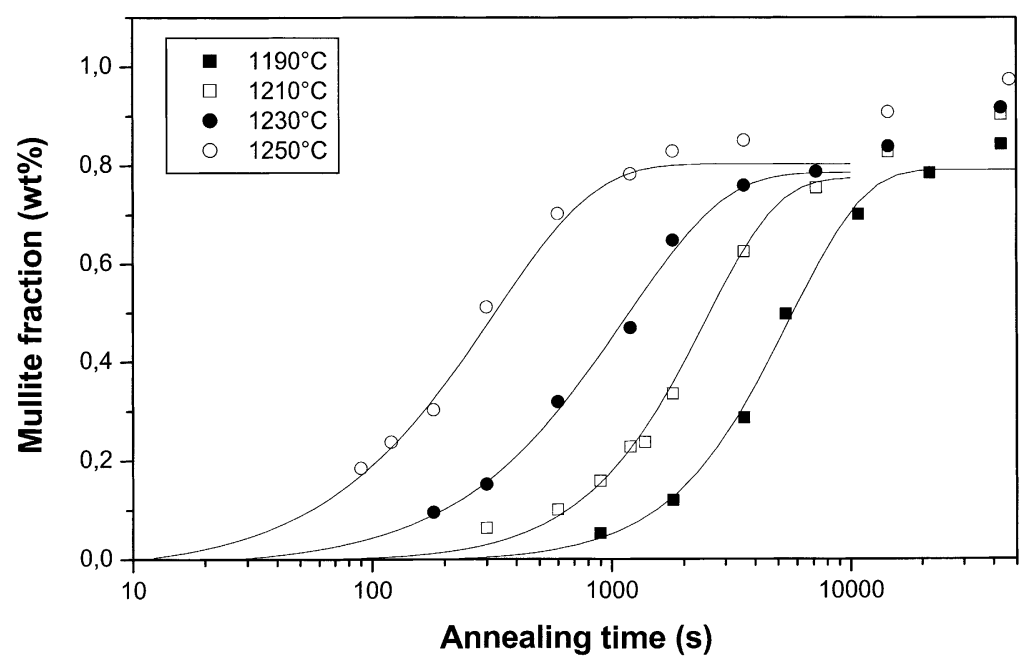

Fig. 2. Isothermal mullite transformation curves for the sample M1 at various temperatures. Mullite weight fractions were determined using 3:2 mullite calibration curve. The full lines are the best fits of the data to Avrami equation.

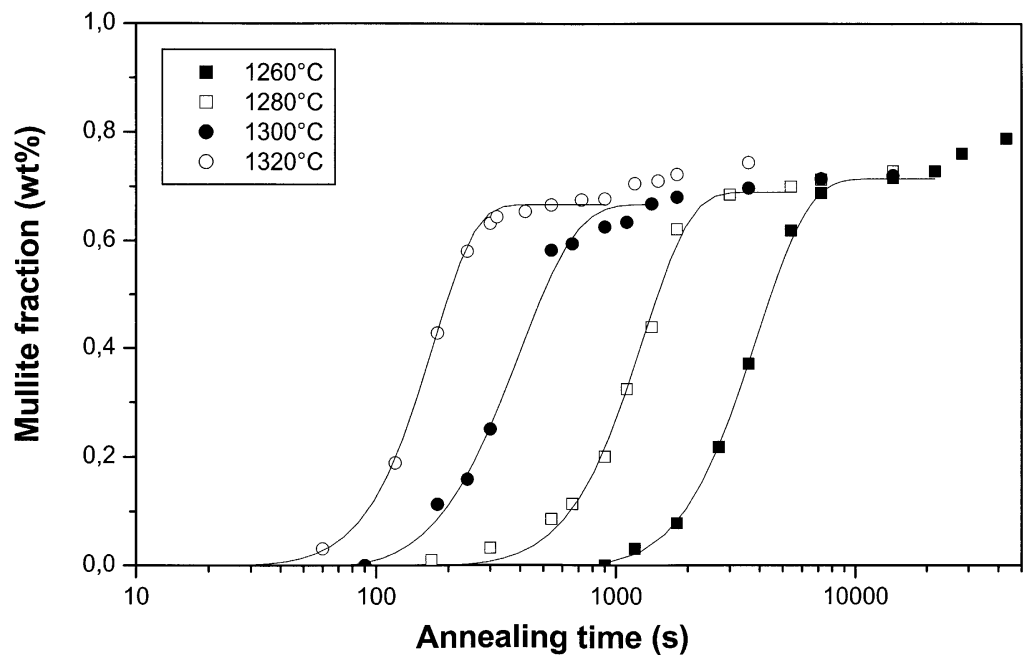

Fig. 3. Isothermal mullite transformation curves for the sample M2 at various temperatures. Mullite weight fractions were determined using $3: 2$ mullite calibration curve. The full lines are the best fits of the data to Avrami equation.

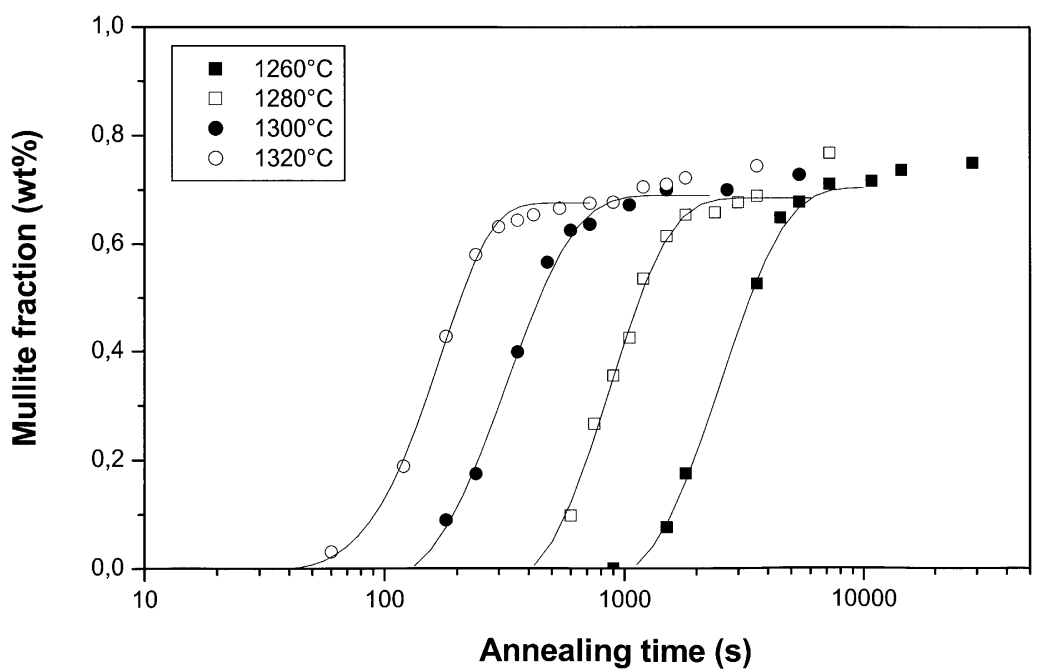

Fig. 4. Isothermal mullite transformation curves for the sample M3 at various temperatures. Mullite weight fractions were determined using 3:2 mullite calibration curve. The full lines are the best fits of the data to Avrami equation. 
It is obvious that only the first steps of the data do have sigmoidal shapes, which allow to evaluate the activation energy for nucleation and growth process, therefore only $\alpha$ up to 0.80 and 0.67 , respectively, were fitted to JMA model. The $k, n$ and $\tau$ are calculated by minimizing the chi-square function and are given in Table 2 . Arrhenius plots for the incubation time, $\tau$, from which the activation energies for nucleation were deduced, are shown in Fig. 5, and the Arrhenius plots for the rate constants, from which the activation energies for nucleation-growth processes were deduced, are shown in Fig. 6. The activation energies for nucleation and nucleation-growth are given in Table 3 . If the fraction of mullite obtained by isothermal treatment is plotted in double logarithmic plot, $\ln (-\ln (1-\alpha))$ vs. $\ln (t)$, it becomes more visible that one single straight line does not fit the experimentall data in the whole time range. Instead, two straight lines with significantly different slopes $n$ referring to an initial and final transformation region can be distinguished. These plots correlated with

Table 2

Rate konstants, $k$, Avrami exponent, $n$, and incubation time, $\tau$

\begin{tabular}{llrlr}
\hline Sample & $\mathrm{T}\left({ }^{\circ} \mathrm{C}\right)$ & $K \times 10^{4}\left(\mathrm{~s}^{1}\right)$ & $n$ & $\tau(\mathrm{s})$ \\
\hline M1 & 1190 & $1.8(2)^{\mathrm{a}}$ & $1.4(2)$ & 162 \\
& 1210 & $4.0(1)$ & $1.36(6)$ & 70 \\
& 1230 & $8.7(4)$ & $1.05(6)$ & 25 \\
M2 & 1250 & $31.0(1)$ & $1.11(7)$ & 10 \\
& 1260 & $2.9(3)$ & $1.8(3)$ & 702 \\
& 1280 & $8.6(2)$ & $2.0(1)$ & 180 \\
& 1300 & $28.4(5)$ & $1.9(4)$ & 70 \\
M3 & 1320 & $63.8(5)$ & $2.18(4)$ & 20 \\
& 1260 & $4.9(7)$ & $1.4(2)$ & 1000 \\
& 1280 & $15.8(8)$ & $1.4(3)$ & 400 \\
& 1300 & $38.0(9)$ & $1.3(3)$ & 125 \\
& 1320 & $87.1(8)$ & $1.7(2)$ & 60 \\
\hline
\end{tabular}

a Numbers in brackets correspond to standard deviation for last digit quoted. the mullite composition, which were obtained by measuring the $a$ unit cell parameter and using the formula: $\mathrm{Al}_{2} \mathrm{O}_{3} \quad(\mathrm{~mol} \%)=1428 \cdot a-1428$ given by $\mathrm{Ban}$ and Okada, ${ }^{19}$ are shown in Fig. 7, for the highest annealing temperatures, 1250 and $1320{ }^{\circ} \mathrm{C}$, respectively. In the same fig. the mean crystallite sizes of mullite are also given. TEM micrographs and electron diffraction patterns of isothermally treated samples at 1250 and $1320{ }^{\circ} \mathrm{C}$ for $6 \mathrm{~h}$ are shown in Fig. 8. The electron diffraction patterns reveal the consistency between the initial size of alumina component with the size of mullite grains. With the increase of particle size of the alumina increases the size of transformed mullite grains.

\section{Discussion}

When the gel containing pseudoboehmite at room temperature (M1) is heated in DTA apparatus at the rate of $5 \mathrm{~K} \mathrm{~min}^{-1}$, mullite crystallizes at $1274{ }^{\circ} \mathrm{C}$. The temperature of mullite formation in the diphasic gel containing $\gamma-\mathrm{Al}_{2} \mathrm{O}_{3}$ (M2) is shifted to $1347{ }^{\circ} \mathrm{C}$, whereas in the gel containing boehmite it is shifted to $1361{ }^{\circ} \mathrm{C}$ (M3), as shown on DTA scans in Fig. 1. The decomposition of pseudoboehmite at $431{ }^{\circ} \mathrm{C}$ and boehmite at $500{ }^{\circ} \mathrm{C}$, respectively, as well as the $\mathrm{Al}-\mathrm{Si}$ spinel formation at $991{ }^{\circ} \mathrm{C}$, are also visible on the DSC scans. Accordingly, gels M2 and M3 could be assigned as type II gels, whereas gel M1 is a mixture of type II and type III gels (Schneider's definition) ${ }^{2}$.

The crystallization kinetics of mullite from the investigated gels can be discussed in terms of two stages (Figs. 2, 3 and 4). In the first stage of the process, mullite formation is fast and $\alpha(\mathrm{t})$ function do have sigmoidal shape, therefore it could be fitted to JMA model [Eq. (2)]. In the second stage, apparently slower increase of mullite is observed. The amount of mullite that crystallizes during the first step was calculated to $\sim 80$

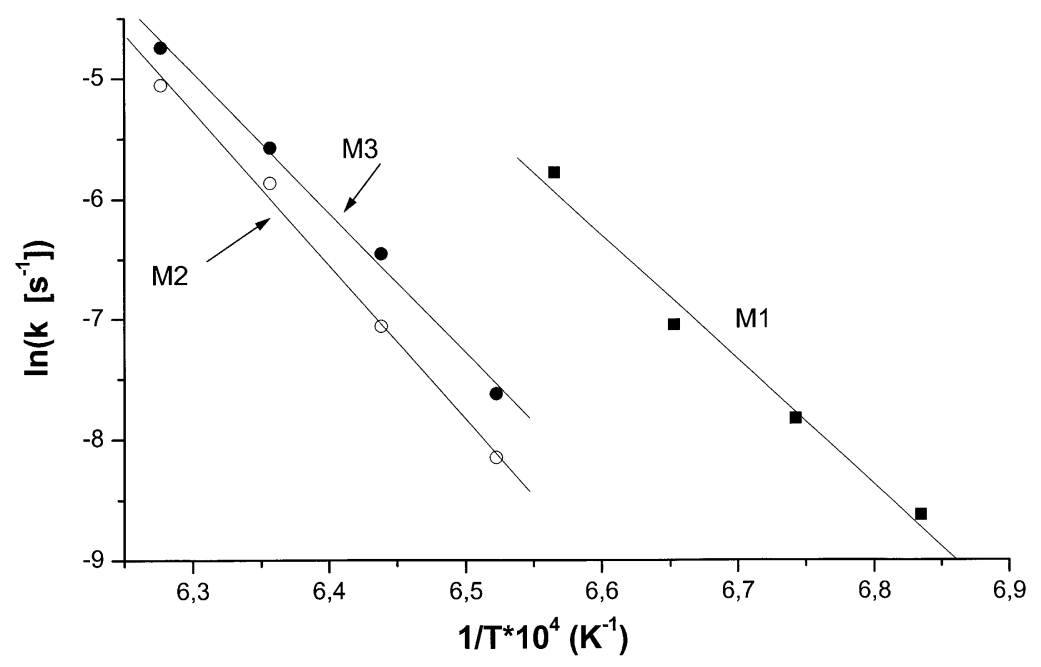

Fig. 5. Arrhenius plots of the incubation time, $\tau$, for nucleation of mullite in samples M1, M2 and M3. 
wt. $\%$ for the gel M1 and about $\sim 67$ wt. $\%$ for the gels M2 and M3, respectively, if the calibration curve prepared with 3:2 mullite was used. Several groups of researchers have provided evidence ${ }^{20-22}$ indicating that diphasic gels appear to initially form a mullite with an approximate composition of $2 \mathrm{Al}_{2} \mathrm{O}_{3} \mathrm{SiO}_{2}$, which then subsequently converts upon further increase of temperature to mullite with an approximate composition of $3 \mathrm{Al}_{2} \mathrm{O}_{3} 2 \mathrm{SiO}_{2}$. It has to be noticed that when we prepared calibration standards with 2:1 mullite, the conversion in sample M1 exceeded $100 \mathrm{wt} \%$, since the composition of mullite studied differentiates from 2:1 mullite. At the beginning of the transformation, it was richer in $\mathrm{SiO}_{2}$ than 2:1 mullite, i.e., $\mathrm{Al}_{2} \mathrm{O}_{3} / \mathrm{SiO}_{2}$ ratio equals 1.86/1 (65 mol\% $\mathrm{Al}_{2} \mathrm{O}_{3}$ ) (Fig. $\left.7 \mathrm{~A}\right)$. The $\mathrm{Al}_{2} \mathrm{O}_{3} /$ $\mathrm{SiO}_{2}$ ratio in the initial formed mullite in samples M2 and $\mathrm{M} 3$ was 1.97:1 (66.4 $\left.\mathrm{mol}_{\%} \mathrm{Al}_{2} \mathrm{O}_{3}\right)$ (Fig. $7 \mathrm{~B}$ and $\mathrm{C}$ ). That means that neither the calibration standards with 3:2 mullite, nor the standards with $2: 1$ mullite are suitable to determine the real extent of mullite transformation. Nevertheless, we decided to use 3:2 calibration curve because so presented experimental data suggest that after some amount of mullite has been formed, (which is greater than 80 or $65 \mathrm{wt} . \%$, respectively, but also smaller than $100 \mathrm{wt} . \%$ ) the mechanism of the process changes. The majority of authors studying the mullite crystallization kinetics use only the change of XRD intensities as an extent of mullite transformation. To our knowledge, there is no systematic investigation about the conversion of 2:1 into $3: 2$ mullite during the isothermal annealing at some temperature. As shown in Fig. 7, the mullite composition is changing with time, hence, the intensities of diffraction lines are also changing. The authors ${ }^{4,5,23}$ who explicitly emphasized that they used 3:2 mullite calibration standards, observed two-, or even three-stage mullite transformation.

The rate constants, $k$, (Table 2) increase with increasing temperature, as expected for a thermally activated, or Arrhenius processes. The samples with $\gamma-\mathrm{Al}_{2} \mathrm{O}_{3}$ (M2) and boehmite-derived $\gamma-\mathrm{Al}_{2} \mathrm{O}_{3}$ (M3) exhibited slightly faster transformation kinetics than the sample derived from aluminum nitrate nonahydrate (M1). A possible explanation for the increase in transformation rates in order of $\mathrm{M} 1<\mathrm{M} 2<\mathrm{M} 3$ could be the different nature of alumina component in the system. In sample $\mathrm{M} 1$, in addition to $\gamma-\mathrm{Al}_{2} \mathrm{O}_{3}$ (which was observed by XRD at about $500{ }^{\circ} \mathrm{C}$ ), Al-Si spinel formation was determined on DTA scan at $1000{ }^{\circ} \mathrm{C}$ (Fig. 1). Studying the mullite formation kinetics in hybrid gels, Huling and Messing ${ }^{6}$ proposed, that when the system is "stabilized" by spinel growth at $1000{ }^{\circ} \mathrm{C}$, the effective diffusitivies in the system decrease, and they obtained rate constants one order of magnitude smaller than for the colloidal gels, although the system exhibited finer scale morphology. The rate constants for M1 (Table 2) reveal a remarkable consistency to those of Huling and Messing for hybrid gel $75 \mathrm{M}_{\mathrm{I}}$. In M2 and M3 samples, no formation of spinel was observed, but the origin of $\gamma-\mathrm{Al}_{2} \mathrm{O}_{3}$ is different. In M2,

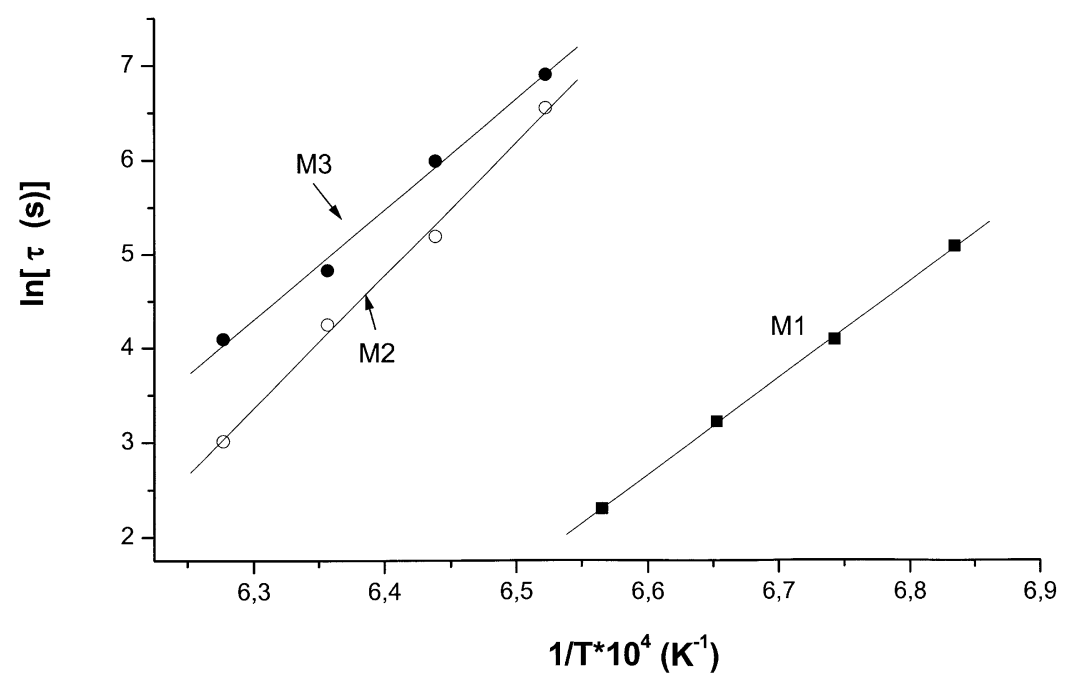

Fig. 6. Arrhenius plots of the rate constants $k$ for nucleation and growth of mullite in the samples M1, M2 and M3.

Table 3

Activation energies and mean value of Avrami exponent, $n$, estimated from the isothermal heat treatments of samples

\begin{tabular}{|c|c|c|c|c|}
\hline Sample & $\mathrm{Al}_{2} \mathrm{O}_{3}$ component & Nucleation $E_{a}^{N}(\mathrm{~kJ} / \mathrm{mol})$ & Nucleation and growth $E_{a}^{N G}(\mathrm{~kJ} / \mathrm{mol})$ & $n$ \\
\hline M1 & Pseudoboehmite (particle size $\sim 10 \mathrm{~nm}$ ) & $885 \pm 11$ & $882 \pm 83$ & 1.2 \\
\hline M2 & $\gamma \mathrm{Al}_{2} \mathrm{O}_{3}$ (particle size $1020 \mathrm{~nm}$ ) & $1174 \pm 52$ & $1063 \pm 50$ & 1.98 \\
\hline M3 & Boehmite $(\gamma \mathrm{AlOOH})($ particle size $3040 \mathrm{~nm})$ & $976 \pm 53$ & $966 \pm 50$ & 1.5 \\
\hline
\end{tabular}



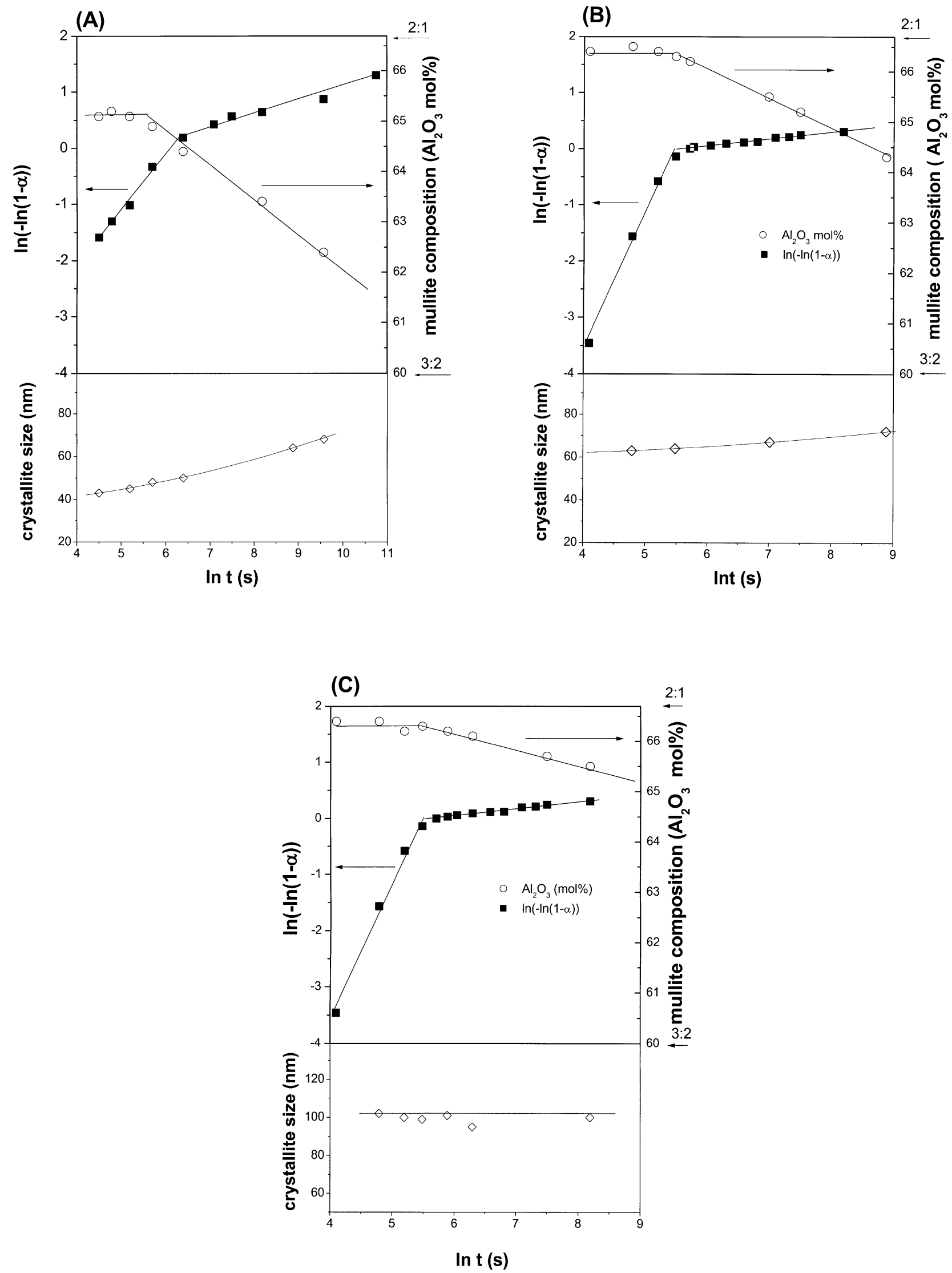

Fig. 7. The change of the mullite composition and crystallite size, and the plot of $\ln (\ln (1 \alpha))$ vs. time. (A) sample $\mathrm{M} 1$ annealed at $1250{ }^{\circ} \mathrm{C}$; (B) sample M2 annealed at $1320{ }^{\circ} \mathrm{C}$; (C) sample M3 annealed at $1320^{\circ} \mathrm{C}$. 

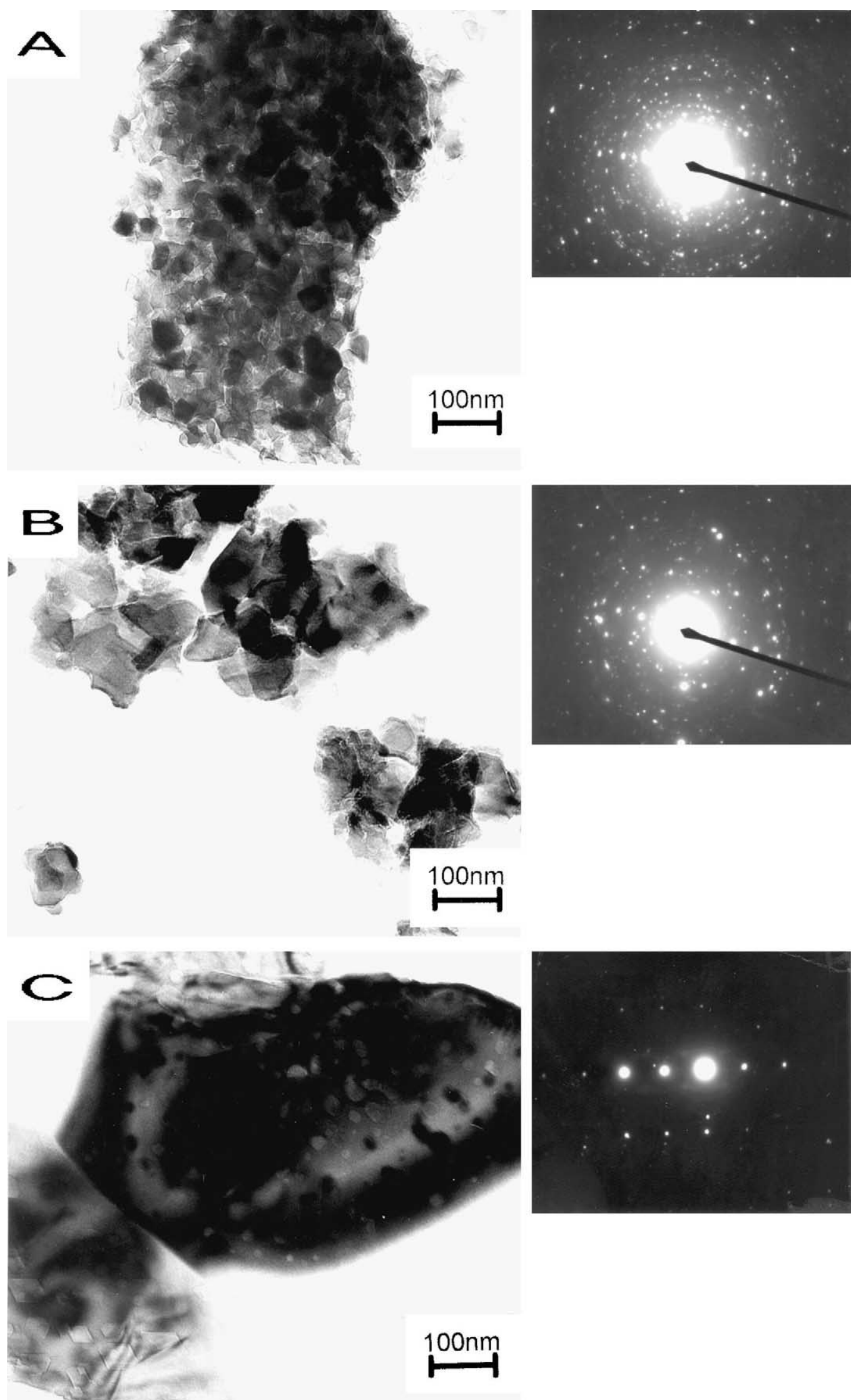

Fig. 8. TEM micrographs and corresponding electron diffraction patterns of the samples heat treated at the largest anneling temperatures for $6 \mathrm{~h}$. (A) sample $\mathrm{M} 1$ heat treated at $1250{ }^{\circ} \mathrm{C}$; (B) sample $\mathrm{M} 2$ heat treated at $1320{ }^{\circ} \mathrm{C}$; (C) sample $\mathrm{M} 3$ heat treated at $1320{ }^{\circ} \mathrm{C}$. 
$\gamma-\mathrm{Al}_{2} \mathrm{O}_{3}$ was added ("Degussa" commercial product), whereas in sample M3 it was formed in situ by decomposition of boehmite. It can be supposed that $\mathrm{OH}$ groups on the surface of added $\gamma-\mathrm{Al}_{2} \mathrm{O}_{3}{ }^{24}$ have the same effect as spinel but in a smaller extent.

The value of the Avrami exponent, $n$, represents the nucleation conditions and the subsequent mechanism and dimensionality of growth. ${ }^{14-16}$ However, the JMA model does not include the presence of porosity, the volume change and other effects which occur during the transformation. All these facts make the interpretation of the time exponent in terms of a physical process in the powders difficult. Nevertheless, the change of mean value of the exponent from $n=1.2$ for the sample M1 through $n=1.5$ for the sample M3 to $n=1.98$ for the sample M2 could be related with the crystal shape and size of alumina particles. In M1 and M3 the alumina component are needles about 10 or $30-40 \mathrm{~nm}$ long, respectively, whereas in $\mathrm{M} 2$ the added $\gamma-\mathrm{Al}_{2} \mathrm{O}_{3}$ exhibited thin plates from 10 to $20 \mathrm{~nm}$ long. The Avrami exponent reveals also a consistency with the results of Huling and Messing, who obtained $n=1.6$ for the same finescaled $75 \mathrm{M}_{\mathrm{I}}$ hybrid gel.

Since the mullite formation in the first stage of $\alpha(t)$ curve followed an Arrhenius relation, plots of $\ln k$ vs. 1/T (Fig. 6) can be used to determine the activation energy for nucleation and growth of mullite. The activation energies for nucleation were deduced from the plot of $1 n$ $\tau$ vs. $1 / T$, (Fig. 5). The longest incubation time, $\tau$, was noticed in the sample with the greatest particle size, and opposite, the shortest incubation time was noticed in the sample with the smallest particle size of alumina, as was expected. As shown in Table 3, the activation energy for nucleation and the activation energy for nucleation and growth are not significantly different within the estimated error. This indicates that processes associated with the nucleation are characterized by the same energy barriers as those related to the nucleation and growth of mullite at a latter sequence of mullite formation. It is consistent with the conclusions found in the literature. $^{3}$ The activation energies increase in the following order:

$M 1<M 3<M 2$

The smallest activation energies are obtained for the precursor containing needles of pseudoboehmite $\sim 10$ $\mathrm{nm}$ long. The $E_{a}^{N}=885 \pm 11 \mathrm{~kJ} / \mathrm{mol}$ for nucleation and $E_{a}^{N G}=882 \pm 83 \mathrm{~kJ} / \mathrm{mol}$, for nucleation-growth are in correspondence with the values obtained by Takei et al. ${ }^{23}$ for the first stage of mullite crystallization in alumina-silica glass fibers. For the sample M3, these values are for about $80 \mathrm{~kJ} / \mathrm{mol}$ higher and are in correspondence with the values obtained by Wei and Halloran for (diphasic) coprecipitated gel. ${ }^{3}$ For sample M2, the $E_{a}^{N}$ and $E_{a}^{N G}$ are for about $200 \mathrm{~kJ} / \mathrm{mol}$ higher. Different activation energies obtained for different precursors could be explained by different characteristic of gels, moreover by different alumina sources, since the same silica source (TEOS-derived amorphous silica) and the same experimental conditions in the determination of $E_{a}$ were applied.

The composition of mullite s.s. obtained by measuring the $a$ unit cell parameter ${ }^{19}$ changes as the reaction proceeds (Fig. 7). At the beginning of the isothermal treatment at $1250{ }^{\circ} \mathrm{C}$ mullite s.s. in the sample $\mathrm{M} 1$ contains about $65 \mathrm{~mol} \% \mathrm{Al}_{2} \mathrm{O}_{3}\left(\mathrm{Al}_{2} \mathrm{O}_{3} / \mathrm{SiO}_{2}=1.86 / 1\right)$ and this value is constant for about $240 \mathrm{~s}$. For longer annealing time the composition of mullite started rapidly to change and after $2 \mathrm{~h}$ of annealing $62.8 \mathrm{~mol} \%$ of alumina in mullite $\left(\mathrm{Al}_{2} \mathrm{O}_{3} / \mathrm{SiO}_{2}=1.69 / 1\right)$ is attained. The decrease of alumina content in the mullite s.s. for M2 and M3 precursors also started after about $240 \mathrm{~s}$ of annealing, but after $2 \mathrm{~h}$ of heat treatment the mullite composition attained about 64.5 and $65.3 \mathrm{~mol} \% \mathrm{Al}_{2} \mathrm{O}_{3}$ $\left(\mathrm{Al}_{2} \mathrm{O}_{3} / \mathrm{SiO}_{2}=1.82: 1\right.$ and $\left.\mathrm{Al}_{2} \mathrm{O}_{3} / \mathrm{SiO}_{2}=1.88: 1\right)$, respectively. It has to be stressed that the change of slope in mullite composition matches with the change in the slope of the plot $\ln (-\ln (1-\alpha))$, for the samples M2 and M3 (Figs. 7A and B) whereas in the sample M1 the mullite composition started to change earlier. It could be attributed to the chemical interdiffusion through the small mullite grains, which started with small time lag or even simultaneously with nucleation and growth in sample M1. The most experimental evidences suggest a silica content in spinel $<10 \mathrm{wt} . \%,{ }^{25-27}$ however, spinel with $18 \mathrm{~mol} \% \mathrm{SiO}_{2},{ }^{28} 2 \mathrm{Al}_{2} \mathrm{O}_{3} \mathrm{SiO}_{2}{ }^{29}$ and $3 \mathrm{Al}_{2} \mathrm{O}_{3} 2 \mathrm{SiO}_{2}{ }^{30}$ composition has also been proposed. The $\mathrm{Al}_{2} \mathrm{O}_{3} / \mathrm{SiO}_{2}$ ratio in this work (1.86 instead of 2) suggests that about $7 \mathrm{wt} . \%$ of silica could be incorporated in the spinel structure.

The composition of mullite s.s. transformed in sample $\mathrm{M} 2$ and M3 at the beginning of annealing at $1320^{\circ} \mathrm{C}$ is the same, but the conversion into 3:2 is slower in M3 containing larger particle size of boehmite-derived $\gamma$ $\mathrm{Al}_{2} \mathrm{O}_{3}$, then in sample M2. Elimination of alumina particles entrapped within large mullite grains in the sample M3 (Fig. 8C) requires chemical interdiffusion over relatively long distances. Hence, a longer time period is required to complete the reaction. Even after $6 \mathrm{~h}$ of annealing at $1320{ }^{\circ} \mathrm{C}$ alumina particles were still entrapped in mullite grains, as shown in Fig. 8C. Studying the crystallization kinetics of mullite in alumina-silica glass fibers, Takei et al. ${ }^{23}$ observed that the transformation of mullite occurs even in three stages, and proceeds via nucleation, nucleation-growth and coalescence of mullite grains. The last process was predominant during the third stage. In our experiments we observed a small or no increase in crystallite size at all, as seen in Fig. 7.

The change of Avrami exponent, $n$, i.e., the change in the slope of the plot $\ln (-\ln (1-\alpha))$ has been observed by $\mathrm{Li}$ and Thomson ${ }^{4,5}$ with diphasic as well as with single- 
phase gels. As mentioned, Takei et al. ${ }^{23}$ observed even three stages of mullite formation. Several possible explanation for the change of $n$ were discussed in literature. Arguments are based on (1) nucleation sites are consumed in initial stage of reaction, ${ }^{14}$ (2) variable nucleation and growth rates occur in different grains, ${ }^{31}$ and (3) impingement of growing grains takes place in the second stage of the process, ${ }^{32}$ which is the most accepted explanation in literature. As can be seen in Fig. 7, in the second stage of the process conversion of 2:1-3:2 mullite occurs. This conversion is faster in the sample containing smaller particle size of added commercial $\gamma-\mathrm{Al}_{2} \mathrm{O}_{3}$ than in the sample containing in situ formed $\gamma-\mathrm{Al}_{2} \mathrm{O}_{3}$ with greater particle size, and is the fastest in the sample with fine pseudoboehmite-derived $\gamma-\mathrm{Al}_{2} \mathrm{O}_{3}$. In the sample $\mathrm{M} 1$ this conversion started even before the first stage of mullite transformation ended.

\section{Conclusion}

The crystallization of mullite in diphasic gels with different alumina component was investigated using isothermal kinetic studies. Two different reaction stages were identified:

(1) the initial nucleation and growth of mullite, and

(2) the final slow conversion at which mullite with approximate 2:1 composition subsequently converts further into $3: 2$.

The initial stage can be described in terms of the Avrami kinetic equation, and processes associated with nucleation are characterized by the same energy barriers as those related to nucleation-growth of mullite at a latter sequence of the first stage. The activation energies for nucleation and growth are consistent with literature values.

When $\mathrm{Al}-\mathrm{Si}$ spinel precedes the mullite formation, greater amount of mullite s.s. transformation follows Avrami model. On the contrary, when a commercial $\gamma-\mathrm{Al}_{2} \mathrm{O}_{3}$ or boehmite-derived $\gamma-\mathrm{Al}_{2} \mathrm{O}_{3}$ is used as a source of alumina, smaller part of $\alpha(\mathrm{t})$ curve has sigmoidal dependence with time.

Apparently smaller increase of mullite was observed in the second stage of crystallization. In this stage the approximate 2:1 mullite transforms further into 3:2 mullite by solid-state reaction. This conversion is faster in the sample containing smaller particle size of commercial $\gamma-\mathrm{Al}_{2} \mathrm{O}_{3}$, then in the sample containing in situ formed $\gamma-\mathrm{Al}_{2} \mathrm{O}_{3}$, and is the fastest in the sample with very fine scale of morphology containing pseudoboehmite-derived $\gamma-\mathrm{Al}_{2} \mathrm{O}_{3}$ and $\mathrm{Al}-\mathrm{Si}$ spinel.

\section{References}

1. Schneider, H., Okada, K. and Pask, J. A., Mullite and Mullite Ceramics. Wiley, New York, 1994.

2. Schneider, H., Voll, D., Saruhan, B., Sanz, J., Schrader, G., Ruscher, C. and Mosset, A., Synthesis and structural character ization of non crystalline mullite precursors. J. Non Cryst. Sol, 1994, 78, 262271.

3. Wei, W. Ch. and Halloran, J. W., Transformation kinetics of diphasic aluminosilicate gels. J. Am. Ceram. Soc., 1988, 71, 581 587.

4. Li, D. X. and Thomson, W. J., Mullite formation kinetics of a single phase gel. J. Am. Ceram. Soc., 1990, 73(4), 964969.

5. Li, D. X. and Thomson, W. J., Mullite formation from non stoichiometric diphasic precursors. J. Am. Ceram. Soc., 1991, 74, 23822387.

6. Huling, J. C. and Messing, G. L., Epitactic nucleation of spinel in aluminosilicate gels and its effect on mullite crystallization. $J$. Am. Ceram. Soc., 1991, 74, 23742381.

7. Hildmann, B. O., Schneider, H. and Schmucker, M., High tem perature behavior of polycrystalline aluminosilicate fibers with mullite bulk composition. II. Kinetics of mullite formation. J. Eur. Ceram. Soc., 1996, 16, 287292.

8. Hong, S. H. and Messing, G. L., Mullite transformation kinetics in $\mathrm{P}_{2} \mathrm{O}_{5}, \mathrm{TiO}_{2}$, and $\mathrm{B}_{2} \mathrm{O}_{3}$ doped aluminosilicate gels. J. Am. Ceram. Soc., 1997, 80(6), 15511559.

9. Sundaresan, S. and Aksay, I. A., Mullitization of diphasic aluminosilicate gels. J. Am. Ceram. Soc., 1991, 74(10), 2388 2392.

10. Lee, J. S. and $\mathrm{Yu}, \mathrm{S}$. C., Mullite formation kinetics of coprecipi tated $\mathrm{Al}_{2} \mathrm{O}_{3} \quad \mathrm{SiO}_{2}$ gels. Mater. Bull. Res., 27 (1992) 405416.

11. Sacks, M. D., Wang, K., Scheiffele, G. W. and Bozkurt, N., Effect of composition on mullitization of $\alpha$ alumina/silica micro composite powders. J. Am. Ceram. Soc., 1997, 80(30), 663672.

12. Johnson, W. A. and Mehl, R. F., Reaction kinetics in processes of nucleation and growth. Trans. AIME, 1939, 135, 416433.

13. Avrami, M., Kinetics of phase change I. J Chem. Phys, 1939, 20, 11031112.

14. Avrami, M., Kinetics of phase change II. J. Chem. Phys, 1940, 8, 212224.

15. Avrami, M., Kinetics of phase change III. J. Chem. Phys, 1941, 9, 177184.

16. Cristian, J. W., The Theory of Transformation in Metals and Alloys, 2nd edn. Pergamon Press, Oxford, 1975.

17. Cullity, B. D., Elements of X ray Diffraction, 2nd edn. Addison Wesley, Reading, MA, 1978.

18. Ivankovic, H., Tkalcec, E., Nass, R. and Schmidt, H., Corre lation of the precursor type with densification behavior and microstructure of sintered mullite ceramics, J. Eur. Ceram. Soc. (in press).

19. Ban, T. and Okada, K., Structure refinement method of mul lite by the Rietveld method and a new method for estimation of chemical composition. J. Am. Ceram. Soc., 1992, 75, 227 230.

20. Low, I. M. and McPherson, R., The origins of mullite formation. J. Mater. Sci., 1989, 24, 926936.

21. Okada, K. and Otsuka, N., Change in chemical composition of mullite formed from $2 \mathrm{SiO}_{2} \cdot 3 \mathrm{Al}_{2} \mathrm{O}_{3}$ xerogel during the formation process. J. Am. Ceram. Soc., 1987, 70(10), C245 C247.

22. Hirata, Y., Sakeda, K., Matsushita, Y., Shimada, K. and Ishi hara, Y., Characterization and sintering behavior of alkoxide derived aluminosilicate powders. J. Am. Ceram. Soc., 1989, 72(6), 9951002.

23. Takei, T., Kameshima, Y., Yasumori, A. and Okada, K., Crys tallization kinetics of mullite in alumina silica glass fibers. J. Am. Ceram. Soc., 1999, 82(10), 29802987. 
24. Yanagida, H., Koumoto, K. and Miyayama, M., The Chemistry of Ceramics. J. Wiley \& Sons, Chichester, New York, 1996.

25. Okada, K. and Otsuka, N., Characterization of the spinel phase from $\mathrm{SiO}_{2} \mathrm{Al}_{2} \mathrm{O}_{3}$.xerogels and the formation process of mullite. J. Am. Ceram. Soc., 1986, 69(9), 652656.

26. Okada, K., Otsuka, N. and Ossaka, J., Characterization of spinel phase formed in the kaolinite mullite thermal sequence. J. Am. Ceram. Soc., 1988, 69(10), C 251 C 253.

27. Sonuparlak, B., Sarikaya, M. and Aksay, I. A., Spinel phase formation during the $980{ }^{\circ} \mathrm{C}$ exothermic reaction in kaolinite to mullite reaction series. J. Am. Ceram. Soc., 1987, 70(11), 837842.

28. Schneider, H., Voll, D., Saruhan, B., Schmuecker, Schaller, T. and Sebald, A., Constitution of the $\gamma$ alumina phase in chemi cally produced mullite recursors. J. Eur. Ceram. Soc., 1994, 13, 441448.

29. Low, I. M. and McPherson, R., The structure and composition of Al Si Spinel. J. Mater. Sci. Lett., 1988, 7, 1189611898.

30. Chakravorty, A. K., Formation of silicon aluminum spinel. $J$. Am. Ceram. Soc., 1979, 62, 120125.

31. Rolett, A. D., Srolowitz, D. J., Doherty, R. D. and Anderson, M. P., Computer simulation of recrystallization in non uniformly deformed metals. Acta Metall, 1989, 37, 627639.

32. Rosen, A., Burton, M. S. and Smith, G. V., Recrystallization of high purity iron. Trans. AIME, 1964, 230, 205215. 